\title{
Resection margin involvement with Crohn's disease and postoperative anastomotic integrity
}

\author{
J.WONG, MD, R.M. PRESHAW, MD, FRCSC, D.F. REID, MD, FRCPC, J.K. KELLY, MB, MRCPATH, FRCPC
}

\begin{abstract}
A prospective double-blind trial was conducted in Crohn's disease subjects in whom a resection was being performed, to assess the hypothesis that marginal disease would adversely influence healing of the anastomosis. Of 106 eligible patients, 51 completed a protocol of pathological assessment of the surgical specimen and a water soluble contrast enema 10 to 15 days after the surgical procedure. Six were found to have radiological leaks and three additional subjects had clinical leaks from the anastomosis. The proportion of leaks, both clinical and radiological, was nine of 54 . There was no trend to increasing rate of anastomotic breakdown with increasing marginal disease. Can J Gastroenterol $1989 ; 3(3): 95-97$
\end{abstract}

Key Words: Anastomotic leaks, Crohn's disease, Marginal disease

\section{Marge de résection dans la maladie de Crohn et intégrité anastomotique postopératoire}

RESUME: Une étude prospective à double insu a été effectuée chez les patients souffrant de maladie de Crohn et subissant une résection, afin de vérifier l'hypothèse selon laquelle la maladie marginale a des effets fâcheux sur la guérison de lanastomose. Sur un groupe de 106 patients admissibles, 51 ont été soumis à un protocole d'évaluation pathologique de la pièce chirurgicale et ont reçu un lavement avec un contraste soluble base d'eau 10 à 15 jours après l'intervention; des fuites radiologiques ont été notées chez six patients et chez trois autres sujets, les fuites provenaient de l'anastomose. La proportion de fuites, cliniques et radiologiques, était de neuf de 54 . Il ne semblait pas y avoir augmentation de la détérioration anastomotique avec une augmentation de la maladie marginale.

Departments of Surgery, Radiology and Pathology, University of Calgary Medical School, Calgary, Alberta

Correspondence and reprints: Dr R.M. Preshaw, University of Calgary, Faculty of Medicine, Health Sciences Centre, 3330 Hospital Drive NW, Calgary, Alberta T2N 4N1.

Telephone (403) 220-6884

Received for publication September 5, 1988. Accepted March 30, 1989
Q Lective surgical intervention in Crohn's disease frequently involves resection of a segment of grossly involved intestine with restoration of continuity by an end-to-end anastomosis. There is considerable controversy over the intraoperative surgical decision on where the intestine should be cut. Some workers maintain that it is advisable to use all possible means, including frozen section, to ensure disease-free margins as this will decrease the incidence of immediate postoperative complications $(1,2)$ and reduce the rate of recurrence (3-12), while others have not found any change in the rate of postoperative complications or of recurrence to correlate with the histological state of the resection margins (13-18).

The authors have examined the short term complications of an intestinal anastomosis in Crohn's disease subjects relative to the presence of disease at the margins in a prospective double-blind trial, using a radiological technique to examine anastomotic integrity. The authors' findings support the view that disease-free margins have little advantage in improving anastomotic healing.

\section{PATIENTS AND METHODS}

In a three year period, all subjects undergoing elective resection of Crohn's 
TABLE 1

Anastomotic integrity related to marginal disease in Crohn's subjects treated by resection

\begin{tabular}{|c|c|c|c|}
\hline & \multicolumn{3}{|c|}{ Margin involvement } \\
\hline & $\begin{array}{l}\text { Both margins } \\
\text { clear }\end{array}$ & $\begin{array}{l}\text { One margin } \\
\text { involved }\end{array}$ & $\begin{array}{l}\text { Both margins } \\
\text { involved }\end{array}$ \\
\hline Anastomosis intact & 29 & 15 & 2 \\
\hline Anastomotic leak & $\begin{array}{c}5 \\
\text { (3 clinical, } \\
2 \text { radiological) }\end{array}$ & $\stackrel{2}{2}$ & $\frac{1}{\text { (radiological) }}$ \\
\hline
\end{tabular}

Ordered $2 \times 3$ contingency table. Null hypothesis; no change in proportion of leaks with increased mar

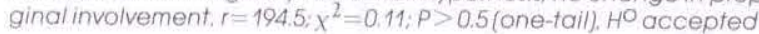

disease by 11 general surgeons were notified to a central office. As far as the authors are aware, these surgeons performed no resections for Crohn's disease during this period which were not reported. If the proposed procedure involved an anastomosis to the colon (commonly ileocolic or colocolic) the patient was asked to cooperate in the trial according to a protocol approved by the University of Calgary Ethics Committee. One hundred and six subjects were approached and 96 agreed to take part in the trial. Of the remaining subjects who agreed to enter, three cases were excluded because the radiological diagnosis of Crohn's disease was not confirmed at laparotomy and a further 17 were excluded because the actual procedure performed differed from that planned and a resection with anastomosis was not performed (commonly an ileostomy was carried out).

Anastomoses were performed according to the preference of the individual surgeon and were both stapled and sewn. Each resection specimen was examined by a pathologist in the fresh, unfixed state. Having been opened, the segment was fixed after stretching on a cork board. Sections were taken as dictated by the gross appearance and in a routine fashion from each resection margin. A written report was made on each specimen without reference to either the operative record or the postoperative progress.

Marginal disease was defined as the microscopic or macroscopic presence of mucosal ulceration or regeneration within $1 \mathrm{~cm}$ of the cut edge, together with either submucosal or transmucosal acute inflammation. Perivascular and serosal acute inflammation was not taken into account, and generalized nonspecific increase in chronic inflammatory cells of the lamina propria was also ignored.

Ten to 15 days after the resection, each eligible subject had a water soluble contrast enema using an iodine containing proprietary contrast agent (iothalamate meglumine $17 \%$ ). The radiologist was informed of the site of the anastomosis, but had no access to the pathological diagnosis or the records of the subject's postoperative course. Prior to the $\mathrm{x}$-ray, oral intake was restricted to fluids for 12 to $18 \mathrm{~h}$, but no attempt was made at other bowel preparation.

Of the 76 subjects eligible following a suitable resection with anastomosis, three developed clinical signs and symptoms of a major anastomotic leak before the 15 th day and, as previously agreed, were not subjected to contrast radiology. In two subjects, the radiologist was unable to reach the site of the anastomosis and the examination was abandoned. A further 11 subjects withdrew from the trial at this stage and nine did not have a contrast enema performed within the 10 to 15 day postoperative period because of miscellaneous problems, including missed appointments and administrative errors. This left 51 subjects in whom both pathological and radiologic assessment was completed and three who had pathological evaluation but developed a clinical leak.

A radiological leak was defined as extravasation of contrast from the presumed anastomotic site for a distance of at least $1 \mathrm{~cm}$. Trends in both clinical and radiological leaks were related to marginal involvement and are listed in Table 1 (19).

\section{RESULTS}

There were no deaths in the postoperative period in this study. Of the 54 subjects who completed pathological evaluation and had contrast radiology, or had a clinical leak, margins were clear of disease in $34(63 \%)$, one margin was involved in $17(31 \%)$ and both margins were involved in three $(6 \%)$. Evidence of disruption of anastomotic integrity were termed 'clinical' in three subjects (clear evidence of leak of bowel contents in first 15 days following surgical procedure) and 'radiological' in another five subjects (extravasation of contrast as defined above 10 to 15 days after the surgical procedure). As noted elsewhere (20-24), radiological leaks were not associated with any discernible effect on the subjects' postoperative course.

The results are tabulated in Table 1 which shows a leak rate (both clinical and radiological) of $17 \%$ when both margins were clear, $13 \%$ when one margin was involved and one leak in two cases where both margins were diseased. Assessment of subgroups according to anatomical segment resected, method of anastomosis (stapled versus sewn), individual surgeon's results, degree of disease activity in the resected intestine, sex or age provided no further useful information.

The three subjects with clinical leaks all were covered with parenteral hydrocortisone in the perioperative period: four of the five subjects with radiological leaks also had steroid cover. Of the 54 subjects who completed the trial, 48 received perioperative steroids. This small series, therefore, does not permit any conclusion about the role of perioperative steroid therapy on the presence or absence of leaks at intestinal anastomoses in Crohn's disease.

The proportion of eligible subjects who chose not to participate in the trial, either when approached initially or who withdrew later, was high (21 of 106) and nine others failed to complete the protocol. Retrospective review of these patients showed no obvious differences from those included in the analysis.

\section{DISCUSSION}

Evidence to suggest that histological Crohn's disease at the intestinal margins 
increased the likelihood of anastomotic leaks has been primarily anecdotal $(1,2)$. The present findings support the view that intestinal anastomoses heal without difficulty even in the presence of active disease (13-18). This concept is upheld by reports $(25,26)$ that plastic procedures carried out in areas of stricture caused by Crohn's disease (stricturoplasty) heal without excess of clinical leaks. Perhaps the finding is also a reflection of the view that Crohn's disease frequently involves most of the gastrointestinal tract, albeit at a low level of activity (27), and hence truly disease-free margins cannot be obtained.

The use of water soluble contrast enemas to examine colonic anastomoses in

\section{REFERENCES}

1. Wolff BG, Beart RW, Frydenberg HB, Weiland LH, Agrez MV, Ilstrup DM. The importance of disease-free margins in resections for Crohn's disease. Dis Colon Rectum 1983;26:239-43.

2. Young S, Smith I, O'Connor J, Bell J, Gillespie G. Results of surgery for Crohn's disease in the Glasgow region 1961-70. Br J Surg 1975;62:528-34.

3. Greenstein AJ, Sachar DB, Pasternack BS, Janowitz HD. Reoperation and recurrence in Crohn's colitis and ileocolitis. Crude and cumulative rates. N Engl J Med 1975;293:685-90.

4. Nygaard K, Fauso O. Crohn's disease. Recurrence after surgical treatment. Scand J Gastroenterol 1977;12:577-83.

5. Karesen R, Serch-Hanssen A, Thoresen BO, Hertzberg J. Crohn's disease: Long term results of surgical treatment. Scand J Gastroenterol 1981;16:57-64.

6. Bergman L, Krause U. Crohn's disease: A long-term study of the clinical course in 186 patients. Scand J Gastroenterol 1977; 12:937-44.

7. Lindhagen T, Ekelund G, Leandoer L, Hildell J, Lindstrom C. Wenckert A. Recurrence rate after surgical treatment of Crohn's disease. Scand J Gastroenterol 1983; 18:1037-44.

8. Homan WP, Dineen P. Comparison of the results of resection, bypass with exclusion for ileocecal Crohn's disease. Ann Surg 1973; 187:530-5.

9. Mekhijian HS, Switz DM, Watts HD, Deren JJ, Katon RM, Beman FM. National Cooperative Crohn's Disease Study: Factors determining recurrence of Crohn's disease after surgery. Gastroenterology 1979;77:907-13. the postoperative period has been used to evaluate intestinal suturing methods (20-22), how low an anterior segmental excision of the rectum should be performed (23) and perioperative nutritional status (25). It has not previously been used to examine anastomoses in Crohn's disease.

After colonic anastomoses, 'radiological' leaks, as defined in this study, appear to have no discernible effect on the subject's recovery from the procedure (20-24). Since these small leaks may be truly benign, it would be possible to argue that any decision on disease-free margins should not be made with reference to radiological leaks. In fact, in this study the three clinical (as opposed to

10. Ellis L, Calhoun P, Kaiser DL, Rudolf LE, Hanks JB. Postoperative recurrence in Crohn's disease. The effect of the initial length of bowel resection and operative procedure. Ann Surg 1984; 199:340-7

11. Atwell JD, Duthie HL, Goligher JC. The outcome of Crohn's disease. Br J Surg 1965;52:966-72.

12. Heen LO, Nygaard K, Bergan A. Crohn's disease. Results of excisional surgery in 133 patients. Scand J Gastroenterol 1984;19:747-54.

13. Hamilton SR, Boitnott JK, Morson BC. Relationship of disease extent and margin lengths to recrudescence of Crohn's disease after ileo-colic anastomosis. Gastroenterology 1981;80:1166.

14. Pennington L, Hamilton SR, Bayless TM, Cameron JL. Surgical management of Crohn's disease. Influence of disease at the margin of resection. Ann Surg 1980;192:311-8.

15. Heuman R, Boeyrd B, Bolin T, Sjodahl R. The influence of disease at the margin of resection on the outcome of Crohn's disease. Br J Surg 1983;70:519-21.

16. Hamilton SR, Reese J, Pennington L, Boitnott JK, Bayless TM, Cameron JL. No role for resection margin frozen sections in the surgical management of Crohn's disease. Gastroenterology 1982;83:1078.

17. Papaioannou N, Piris J, Lee ECG, Kettlewell MGW. The relationship between histological inflammation in the cut ends after resection of Crohn's disease and recurrence. Gut 1979;20:A916. radiological) leaks occurred in subjects in whom the margins were free from disease (Table 1).

During the three year period of this study, 106 patients were identified who were electively proposed for a resection of a segment of Crohn's disease with an anastomosis. Of this group only 51 completed the protocol for a postoperative water soluble enema. Twenty-one patients refused to participate and the others were excluded for miscellaneous reasons. After review of the results, it appeared unlikely that continuation of the study to increase the numbers of participants would add significantly to the conclusions and the trial was terminated.

18. Speranza V, Simi M, Leardi S, Del Papa M. Recurrence of Crohn's disease after resection. Are there any risk factors? J Clin Gastroenterol 1986;8:640-6.

19. Siegel S. Nonparametric Statistics for the Behavioural Sciences. New York: McGraw-Hill, 1956

20. Irvin TT, Goligher JC, Johnston D. A randomized prospective clinical trial of single-layer and two-layer inverting intestinal anastomoses. $\mathrm{Br}$ J Surg 1973:60:457-60.

21. Everett WG. A comparison of one layer and two layer techniques for colorectal anastomosis. Br J Surg 1975:62:135-40.

22. Goligher JC, Lee PWG, Simpkins KC, Lintott DJ. A controlled comparison of one- and two-layer techniques of suture for high and low colorectal anastomoses. Br J Surg 1977;64:609-14.

23. Goligher JC, Graham NG, De Dombal FT Anastomotic dehiscence after anterior resection of rectum and sigmoid. Br J Surg 1970;57:109-18.

24. Preshaw RM, Attisha RP. Hollingsworth WJ, Todd JD. Randomized sequential trial of parenteral nutrition in healing of colonic anastomoses in man. Can J Surg 1979;22:437-9.

25. Wolff BG. Crohn's disease: The role of surgical treatment. Mayo Clin Proc 1986;61:292-5.

26. Alexander-Williams J. New directions for future research: Surgical/clinical. In: Rachmilewitz D, ed. Inflammatory Bowel Disease, Vol 3. London: Martinus Nijhoff, 1982:301-8.

27. Janowitz HD. Crohn's disease -50 years later. N Engl J Med $1981 ; 304 ; 1600-2$. 


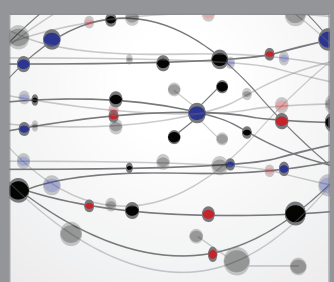

The Scientific World Journal
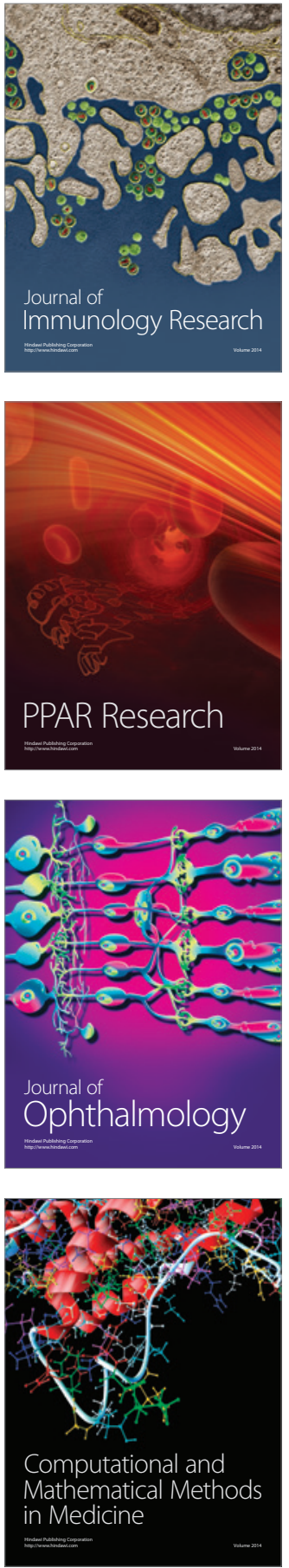

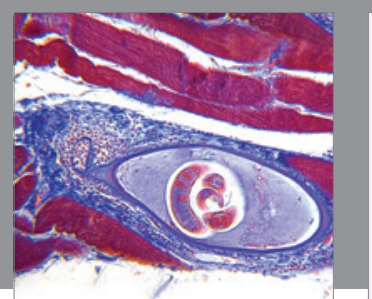

Gastroenterology Research and Practice

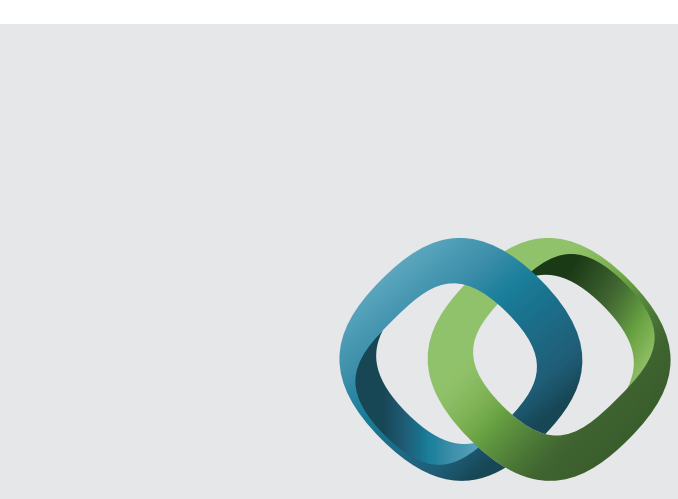

\section{Hindawi}

Submit your manuscripts at

http://www.hindawi.com
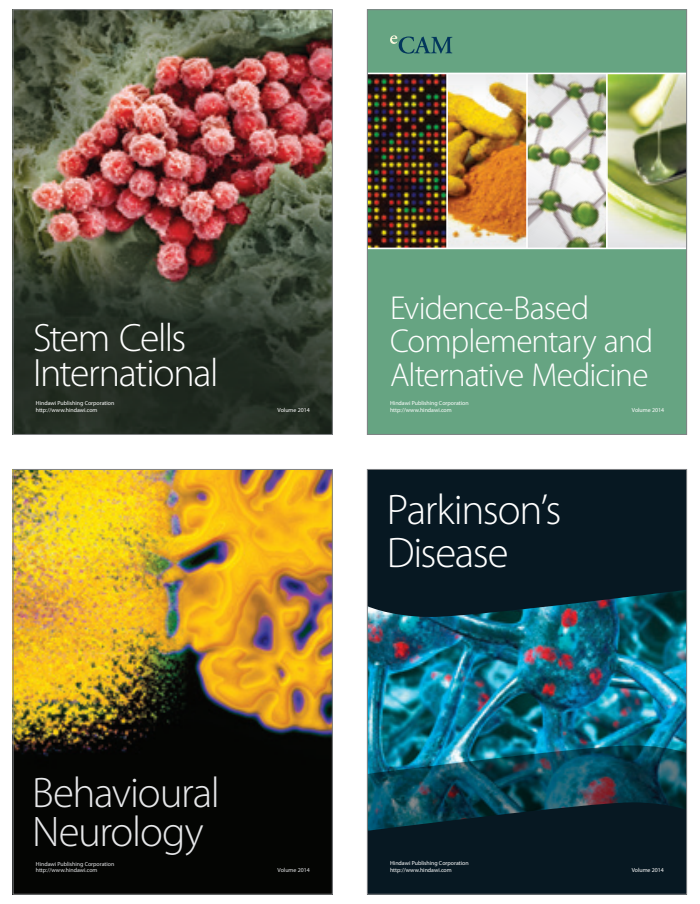
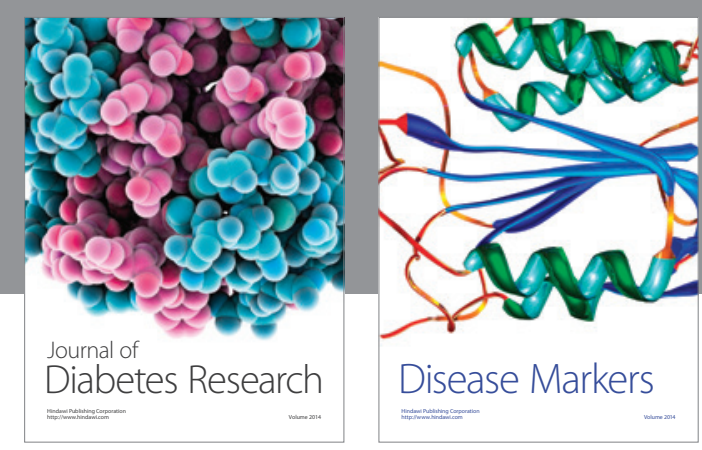

Disease Markers
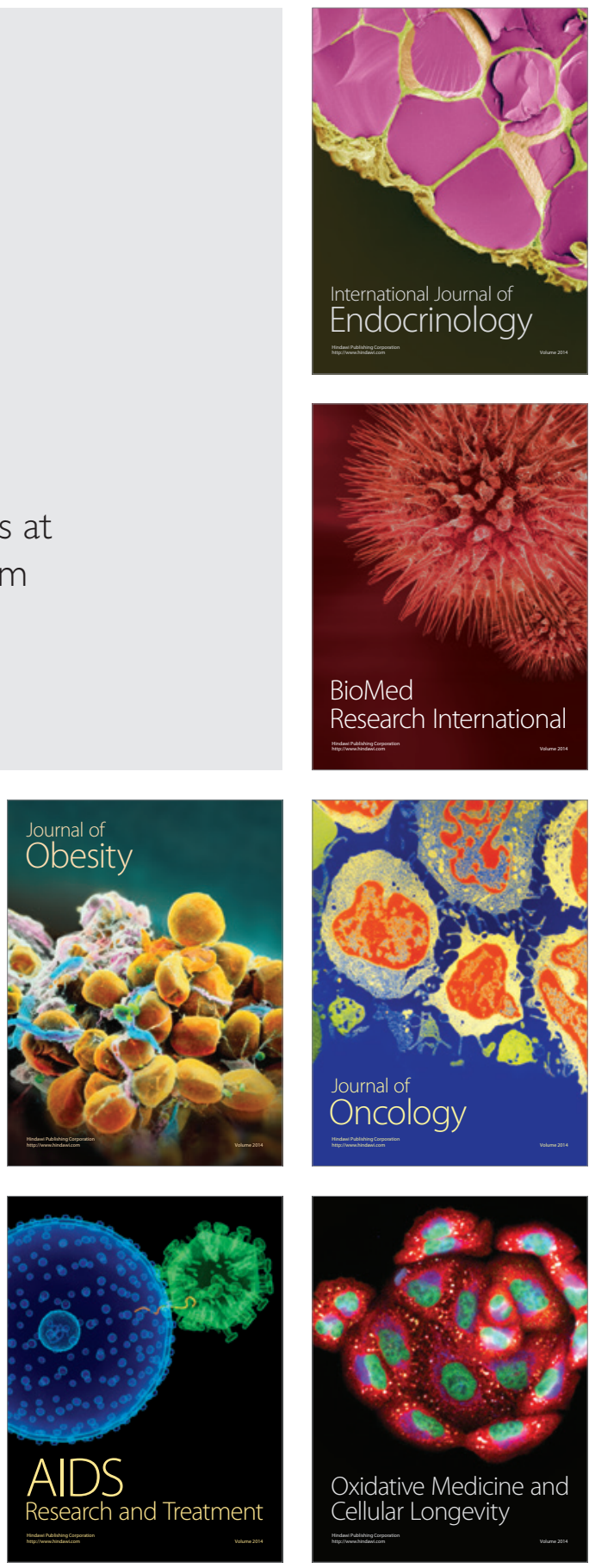